\title{
Titanium(IV) hydrate based on chitosan template for defluoridation from aqueous solution
}

\author{
Jie Liu ${ }^{\mathrm{a}, \mathrm{b}}$, Wan-Yi Lic ${ }^{\mathrm{c}, \mathrm{d}}$, Yunguo Liu ${ }^{\mathrm{a}, \mathrm{b}, *}$, Qinghui Zeng ${ }^{\mathrm{c}, \mathrm{e}}$, Song Hong ${ }^{\mathrm{c}, \mathrm{f}}$ \\ a College of Environmental Science E' Engineering, Hunan University, Changsha 410082, PR China \\ ${ }^{\mathrm{b}}$ Key Laboratory of Environmental Biology and Pollution Control (Hunan University), Ministry of Education, Changsha 410082, PR China \\ ' School of Resource and Environmental Science, Wuhan University, Wuhan 430079, PR China \\ d Department of Chemical Engineering, Columbia University, New York, NY 10027, USA \\ ${ }^{\mathrm{e}}$ Research Center for Eco-Environmental Sciences, Chinese Academy of Sciences, Beijing 100085, PR China \\ ${ }^{\mathrm{f}}$ Hubei Biomass-Resource Chemistry and Environmental Biotechnology Key Laboratory, Wuhan University, Wuhan 430079, PR China
}

\section{A R T I C L E I N F O}

\section{Article history:}

Received 10 July 2013

Received in revised form 6 November 2013

Accepted 8 December 2013

Available online 16 December 2013

\section{Keywords:}

Fluoride sorption

Chitosan

Biocomposites

Titanium hydrate

Nonlinear

\begin{abstract}
A B S T R A C T
A cost effective bio-adsorbent, titanium(IV) hydrate based on chitosan template (Ti-CHI), was synthesized using $\mathrm{Ti}\left(\mathrm{SO}_{4}\right)_{2}$ and chitosan for defluoridation from aqueous solutions. The Ti-CHI material was characterized using FTIR, SEM with EDX, XRD, XPS and Zeta potential. The adsorption kinetics of fluoride onto Ti-CHI followed pseudo-second-order and intra-particle diffusion models. The Ti-CHI was effective for defluoridating systems with low fluoride concentrations $(4.52 \mathrm{mg} / \mathrm{L})$, exhibiting a $87.50 \%$ removal rate and permitting a residual fluoride concentration $(0.55 \mathrm{mg} / \mathrm{L})$. The most stable $\mathrm{pH}$ range for fluoride removal was from 4 to 9 . After combining the results of $\mathrm{pH}$ effects, FTIR and Zeta potential, the - NH groups and $\mathrm{Ti}-\mathrm{OH}$ groups were revealed as the fluoride adsorption sites on $\mathrm{Ti}-\mathrm{CHI}$. In addition, the carbonate ions present in the aqueous solutions adversely impact the fluoride adsorption. The Langmuir, Freundlich, and Langmuir-Freundlich models were used to illustrate the isotherms of the adsorption process. The adsorption of fluoride onto Ti-CHI fits the Langmuir and Langmuir-Freundlich isotherm models well. The maximum adsorption capacity for fluoride on the Ti-CHI was $16.12 \mathrm{mg} / \mathrm{g}$. Thermodynamic studies revealed that the adsorption process was spontaneous.
\end{abstract}

(C) 2013 Elsevier B.V. All rights reserved.

\section{Introduction}

High fluoride levels are a major threat to drinking water production in many countries worldwide [1]. Consuming too much fluoride-contaminated drinking water can cause endemic fluorosis. Individuals suffering from fluorosis may develop symptoms that include periosteal proliferation, osteoporosis and dental illnesses $[2,3]$. A comprehensive literature review reveals that defluoridation through adsorption onto various materials is promising because it is cost effective in the context of the medium and running costs and it is characterized by easy operation, high adsorption capacity, recyclability, numerous useful cycles, and possible regeneration [4].

Titanium-derived adsorbents are widely used to treat arseniccontaminated underground water and known to have potential for defluoridation. Yuchi and Matsuo used titanium (IV) that was

\footnotetext{
* Corresponding author at: College of Environmental Science \& Engineering, Hunan University, Changsha 410082, PR China. Tel.: +86 731 88649208; fax: +8673188649208.

E-mail addresses: ljluck@126.com (J. Liu),wanyili@whu.edu.cn (W.-Y. Li), environmentalist13@126.com (Y. Liu),xiaohui900108@yahoo.cn (Q. Zeng), songhongpku@126.com (S. Hong).
}

chemically immobilized in a gel-phase for fluoride sorption but discovered that this material has a limited adsorption capacity due to its tendency to hydrolyze [5]. Wajima and Umeta et al. prepared a gel-like titanium hydroxide-derived adsorbent for defluoridation. They found that the adsorption behavior of fluoride ions on this adsorbent was $\mathrm{pH}$-dependent. When $3 \leq \mathrm{pH} \leq 9$, the fluoride ion content linearly decreased to zero as the $\mathrm{pH}$ increased [6]. The Fe-Ti oxide nano-adsorbent synthesized by Chen et al. showed a high affinity for fluoride ions, but the effects of $\mathrm{pH}$ on its sorption were not reported in their work [7].

The applications of titanium-derived adsorbents in defluoridation are limited when exposed to both a low $\mathrm{pH}$ and fluoride ions in solution because these conditions accelerate the titanium release [8]. Chitosan has the highest metal coordinating ability among the natural polymers [9]. Modifying titanium-derived adsorbents with chitosan would overcome the limitations of these adsorbents. Thakre et al. prepared a chitosan-based mesoporous Ti-Al binary metal oxide to adsorb fluoride. Their study revealed obvious enhancements in the adsorption capacity after integrating the chitosan. Jagtap et al. used titanium isopropoxide as a raw material for preparing chitosan-based adsorbents for defluoridation [10]. The adsorbents reduced the fluoride concentration from $5 \mathrm{mg} / \mathrm{L}$ to $1.27 \mathrm{mg} / \mathrm{L}$ but still could not achieve the acceptable limit for 
fluoride in drinking water in most fluoride damaged countries (1 mg/L) [4]. Therefore, titanium-derived adsorbents should be improved in terms of their cost effectiveness and should have stable defluoridation performance under different $\mathrm{pH}$ conditions.

In this study, we use chitosan as a template and $\mathrm{Ti}\left(\mathrm{SO}_{4}\right)_{2} \cdot 4 \mathrm{H}_{2} \mathrm{O}$ as a titanium(IV) source to prepare a new defluoridation adsorbent for fluoride-contaminated aqueous solutions to meet the drinking water standard. $\mathrm{Ti}\left(\mathrm{SO}_{4}\right)_{2} \cdot 4 \mathrm{H}_{2} \mathrm{O}$ is much cheaper than titanium isopropoxide [11]. This work evaluated the defluoridation capacity (DC) of this adsorbent and investigated its surface characteristics and fluoride adsorption mechanism using surface examination techniques. Moreover, a nonlinear method was applied to the experimental data to determine the best-fitting isotherm and kinetic models.

\section{Materials and methods}

\subsection{Chemicals}

All chemicals were of analytical grade. The experimental equipment was washed with deionized water. When required, the experimental reagents were diluted with ultra-pure water. The chitosan was purchased from Zhejiang Aoxing Biotechnology Co. Ltd., Zhejiang, P. R. China and had a 90\% degree of deacetylation. The nano $\mathrm{TiO}_{2}$, titanium(IV) sulfate $\left(\mathrm{Ti}\left(\mathrm{SO}_{4}\right)_{2}\right)$, sodium fluoride $(\mathrm{NaF})$, sodium chloride $(\mathrm{NaCl})$, sodium sulfate $\left(\mathrm{Na}_{2} \mathrm{SO}_{4}\right)$, sodium nitrate $\left(\mathrm{NaNO}_{3}\right)$, sodium carbonate $\left(\mathrm{Na}_{2} \mathrm{CO}_{3}\right)$, sodium bicarbonate $\left(\mathrm{NaHCO}_{3}\right)$, sodium phosphate $\left(\mathrm{Na}_{3} \mathrm{PO}_{4}\right)$, hydrochloric acid $(\mathrm{HCl})$, sodium hydroxide $(\mathrm{NaOH})$, sodium citrate $\left(\mathrm{Na}_{3} \mathrm{C}_{6} \mathrm{H}_{5} \mathrm{O}_{7} \cdot 2 \mathrm{H}_{2} \mathrm{O}\right)$, urea, acetic anhydride, sodium citrate and oxalic acid were purchased from Sinopharm Chemical Reagent Co. Ltd.

\subsection{Preparation of adsorbents}

Adsorbent 1: $5 \mathrm{~g}$ of titanium(IV) sulfate and $6 \mathrm{~g}$ of urea were dissolved in $100 \mathrm{~mL}$ of deionized water in a 3-necked flask and stirred for $1 \mathrm{~h}$ at $333 \mathrm{~K}$. Chitosan-acetic anhydride solution (2\%) was subsequently added to the flask, and the $\mathrm{pH}$ was adjusted to 7 using $2 \mathrm{M}$ ammonia. After $3 \mathrm{~h}$, the deposits in the flask were centrifuged and washed with deionized water until all sulfate ions were removed. Finally, the deposits were dried at $353 \mathrm{~K}$ for $6 \mathrm{~h}$ and ground. The titanium(IV) hydrate based on the chitosan template (Ti-CHI) was obtained.

Adsorbent 2: The Ti-CHI was calcined in a muffle furnace at 450 for $2 \mathrm{~h}$ to obtain the cTi-CHI.

Adsorbent 3: The nano $\mathrm{TiO}_{2}$ and chitosan were magnetically stirred in a $10 \mathrm{M} \mathrm{NaOH}$ solution. After the mixture was well mixed, it was placed in a high pressure reactor and heated at $160-180^{\circ} \mathrm{C}$ for $24 \mathrm{~h}$. Afterward, the mixture was centrifuged and washed with deionized water until the washings were neutral. Finally, the mixture was dried at $353 \mathrm{~K}$ for $6 \mathrm{~h}$ and ground to obtain the nTi-CHI.

\subsection{Characterization}

The Ti-CHI was identified using several non-destructive techniques: scanning electron microscopy (SEM, Quanta 200, FEI Co.) with energy dispersive X-ray spectroscopy (EDX, accessories of Quanta 200, FEI Co.), Fourier transform infrared spectroscopy (FTIR, 5700 FTIR, Nicolet Co.), X-ray diffraction (XRD, D/MAX- $\gamma$ instrument), X-ray photoelectron spectroscopy (XPS, KRATOS XSAM800, Shimadzu Co.) and Zeta potential (zen 3600, Malvern Co.). The surface charges were measured using Zeta-Sizer; these values were based on the electrophoretic mobility of the adsorbents in aqueous media at different pHs. Each measurement was performed in an aqueous solution with a constant ionic strength $\left(0.1 \mathrm{M} \mathrm{NaNO}_{3}\right)$; the $\mathrm{pH}$ was adjusted using $\mathrm{NaOH}$ or $\mathrm{HNO}_{3}$. Each Zeta potential was measured 4 times; the average values were used in the Zeta potential-pH plot.

The fluoride analysis was carried out using a fluoride-selective electrode method (ASTM D1179-B). Total ionic strength adjustment buffer (I) (TISAB (I)) solution was used as a buffer, maintaining the $\mathrm{pH}$ and background ion concentration while analyzing the $\mathrm{F}^{-}$concentration. This medium was prepared by dissolving $58.5 \mathrm{~g}$ of $\mathrm{NaCl}$, $0.3 \mathrm{~g}$ of $\mathrm{Na}_{3} \mathrm{C}_{6} \mathrm{H}_{5} \mathrm{O}_{7} \cdot 2 \mathrm{H}_{2} \mathrm{O}$ and $57 \mathrm{~mL}$ of glacial acetic acid in DI water before adjusting the $\mathrm{pH}$ to $5.0-5.5$ with $10 \mathrm{M} \mathrm{NaOH}$ and adding DI water until the solution reached $1000 \mathrm{~mL}$.

\subsection{Adsorption of fluoride onto adsorbents}

A stock solution of $1000 \mathrm{mg} \mathrm{NaF/L}$ was prepared for the various aqueous fluoride dilutions. The experiments for DC evaluation of the adsorbents were carried out as follows: $1 \mathrm{~g}$ of adsorbent was added in $1000 \mathrm{~mL}(40 \mathrm{mg} \mathrm{NaF} / \mathrm{L})$ of aqueous fluoride solution without adjusting the $\mathrm{pH}$; the mixture was stirred for $3 \mathrm{~h}$ at room temperature. At selected time intervals, approximately $8 \mathrm{~mL}$ of the suspension was withdrawn to assess the $\mathrm{F}^{-}$concentration. The equilibrium sorption experiment was carried out as follows: after adding $0.1 \mathrm{~g}$ of adsorbent and $50 \mathrm{~mL}$ of a fluoride aqueous solution with a known concentration to a flask, the mixtures were oscillated in a shaking water bath at 283, 293, 303, 313 , and $323 \mathrm{~K}$ under $200 \mathrm{rmp}$ for $3 \mathrm{~h}$, respectively; the residual $\mathrm{F}^{-}$concentration was tested. The $\mathrm{pH}$ effects were studied using equilibrium sorption experiments at known $\mathrm{pH}$ values. The $\mathrm{pH}$ values were adjusted using aqueous $1 \mathrm{M} \mathrm{HCl}$ or $\mathrm{NaOH}$ solutions. The impact of the co-anions was studied by adding $\mathrm{NaCl}$, $\mathrm{Na}_{2} \mathrm{SO}_{4}, \mathrm{NaNO}_{3}, \mathrm{Na}_{2} \mathrm{CO}_{3}, \mathrm{NaHCO}_{3}$ and $\mathrm{Na}_{3} \mathrm{PO}_{4}$ during equilibrium sorption.

\subsection{Data processing methods}

The equilibrium sorption capacity could be calculated using the following expression:

$q_{e}=\frac{\left(c_{0}-c_{e}\right) V}{m}$

where $q_{e}$ is the equilibrium adsorption capacity of fluoride adsorbed per unit mass of Ti-CHI $(\mathrm{mg} / \mathrm{g}) ; c_{0}$ and $c_{e}$ are the initial $(\mathrm{mg} / \mathrm{L})$ and equilibrium fluoride concentrations $(\mathrm{mg} / \mathrm{L})$, respectively; $V$ is the volume of the fluoride solution (L); and $m$ is the mass of the Ti-CHI $(\mathrm{g})$. For the remainder of the present work, $q_{e}$ is the defluoridation capacity used to evaluate the defluoridation performance of Ti-CHI.

In this work, the Langmuir, Freundlich and Langmuir-Freundlich isotherm models were adopted to model the adsorption equilibrium data [18]. The pseudofirst-order, pseudo-second-order and intra-particle diffusion $[19,20]$ models were employed while assessing the adsorption kinetics. A nonlinear method was used to find the bestfitting isotherms through a trial-and-error procedure using Origin 8.6.

In general, based on the magnitude of the coefficient of determination for the linear or nonlinear regression, the accuracy of the fit of the experimental equilibrium data to an isotherm model could be assessed [21]. The coefficient of determination $\left(r^{2}\right)$ was obtained:

$r^{2}=\frac{\sum\left(q_{m}-\bar{q}_{e}\right)^{2}}{\sum\left(q_{m}-\bar{q}_{e}\right)^{2}+\sum\left(q_{m}-q_{e}\right)^{2}}$

where $q_{m}$ is the equilibrium capacity obtained from the isotherm model, $q_{e}$ is the equilibrium capacity obtained from experiment, and $\bar{q}_{e}$ is the average of the $q_{e}$ values. 
Table 1

Different synthetic processes for Ti-CHI, cTi-CHI and nTi-CHI and their defluoridation capacities.

\begin{tabular}{|c|c|c|c|c|c|}
\hline Adsorbent no. & Adsorbent name & Ti resource & Reactants & Thermal treatment $\left({ }^{\circ} \mathrm{C}\right)$ & $\begin{array}{l}\text { Defluoridation } \\
\text { capacity (mg/L) }\end{array}$ \\
\hline 1 & Ti-CHI & $\mathrm{Ti}\left(\mathrm{SO}_{4}\right)_{2}$ & Chitosan, urease, acetic anhydride & 80 & 12.11 \\
\hline 2 & cTi-CHI & $\mathrm{Ti}\left(\mathrm{SO}_{4}\right)_{2}$ & Chitosan, urease, acetic anhydride & 450 & 6.81 \\
\hline 3 & nTi-CHI & Nano $\mathrm{TiO}_{2}$ & Chitosan, $\mathrm{NaOH}$ & $160-180$ & 4.31 \\
\hline
\end{tabular}

\section{Results and discussion}

\subsection{Optimal adsorbent}

The optimal adsorbent should have a high affinity to the sorbate and a high specific surface area. We either used nano $\mathrm{TiO}_{2}$ and $\mathrm{Ti}\left(\mathrm{SO}_{4}\right)_{2}$ as Ti sources while synthesizing the Ti-CHI and nTi-CHI bio-adsorbents for fluoride sorption. We also calcined the Ti-CHI bio-adsorbent at $450^{\circ} \mathrm{C}$ to compare the function of the chitosan. These three adsorbents were exposed to aqueous $\mathrm{F}^{-}$ions for $24 \mathrm{~h}$. Table 1 shows the DC of the adsorbents. The Ti-CHI had the highest DC of the three adsorbents, followed by cTi-CHI and nTi-CHI. While synthesizing Ti-CHI (Eqs. (3)-(5)), urea uniformly heated $\mathrm{Ti}\left(\mathrm{SO}_{4}\right)_{2}$ and titanium hydrate generated on the chitosan template. Therefore, the titanium hydrate has a better affinity for $\mathrm{F}^{-}$. The $\mathrm{DC}$ of the cTi-CHI is lower than that of nTi-CHI due to the absence of chitosan, which would enhance the surface porosity of the adsorbents [12]. The Ti-CHI was selected as the fluoride adsorbent because it has the advantages of both titanium hydrate and chitosan.

$$
\begin{aligned}
& \mathrm{CO}\left(\mathrm{NH}_{2}\right)_{2}+\mathrm{H}_{2} \mathrm{O} \rightarrow \mathrm{NH}_{4} \mathrm{OH}+\mathrm{CO}_{2} \\
& 4 \mathrm{NH}_{4} \mathrm{OH}+\mathrm{Ti}\left(\mathrm{SO}_{4}\right)_{2} \rightarrow \mathrm{Ti}(\mathrm{OH})_{4}+2\left(\mathrm{NH}_{4}\right)_{2}+\mathrm{SO}_{4} \\
& \mathrm{Ti}(\mathrm{OH})_{4} \rightarrow \mathrm{TiO}_{2}+2 \mathrm{H}_{2} \mathrm{O}
\end{aligned}
$$

\subsection{Characterization}

\subsubsection{SEM with EDX}

The surface morphology and elemental constituents of $\mathrm{Ti}-\mathrm{CHI}$ were confirmed using SEM with EDX analysis. Fig. 1(a and b) shows the SEM photographs of chitosan and Ti-CHI, respectively. Compared to the chitosan, the Ti-CHI had a very different morphology; it changed from being long strips of irregular, scattered flakes into aggregated, spherical particles. Furthermore, the particle size of new adsorbent was much smaller than that of the original chitosan. The Ti-CHI particle size was $200 \mathrm{~nm}$, which was approximately $1 / 125$ that of chitosan, and could reach submicron levels. Fig. 2
Table 2

Elemental constituents of Ti-CHI.

\begin{tabular}{lll}
\hline Element & Wt\% & At.\% \\
\hline $\mathrm{C}$ & 24.23 & 35.71 \\
$\mathrm{~N}$ & 13.76 & 17.39 \\
$\mathrm{O}$ & 31.53 & 34.89 \\
$\mathrm{~S}$ & 04.14 & 02.28 \\
$\mathrm{Ti}$ & 26.34 & 09.73 \\
\hline
\end{tabular}

shows the energy dispersive X-ray analysis diagram of the chitosan and the modified material. Ti-CHI contained $\mathrm{C}, \mathrm{N}, \mathrm{O}, \mathrm{S}$, and Ti. The $\mathrm{Ti}$ and $\mathrm{S}$ came from the titanium sulfate, whereas $\mathrm{N}$ came from the urea. In Table 2, the elemental constituents of $\mathrm{Ti}-\mathrm{CHI}$ reveal that Ti-CHI was rich in titanium.

\subsection{2. $X R D$}

XRD was used to determine the crystalline structure of the materials. The XRD patterns of the $\mathrm{CHI}$ and Ti-CHI are shown in Fig. 3. The XRD pattern of chitosan contains a dominant crystalline peak at a 2 theta value of $10^{\circ}$. This major crystalline peak is also observed in the pattern for $\mathrm{Ti}-\mathrm{CHI}$, but the peaks for titanium oxide are not observed, suggesting that the titanium oxide had an amorphous $\mathrm{Ti}(\mathrm{OH})_{4}$ structure $[9,11]$.

\subsection{3. $X P S$}

The XPS technique has been applied to further identify the chemical status of the biocomposite. Using the curve-fitting program (XPSPEAK v4.1), curve fitting of the Ti 2 p peak was performed by using a Shirley background, Gauss-Lorentzian character, and a full width at half maximum (FWHM). As can be seen from Fig. 4, Ti 2 p3/2 and 2 p1/2 peak position were measured at 458.50 [13] and $464.32 \mathrm{eV}$ [14], respectively. The Ti $2 \mathrm{p}$ spectrum of the $\mathrm{Ti}-\mathrm{CHI}$ is dominated by species in the Ti (IV) oxidation state with the presence of a small contribution of reduced species Ti(III) [15]. This $\mathrm{Ti}(\mathrm{III})$ species can be assigned to TiN formation by bonding of Ti(III) and $\mathrm{NH}$ groups on chitosan.

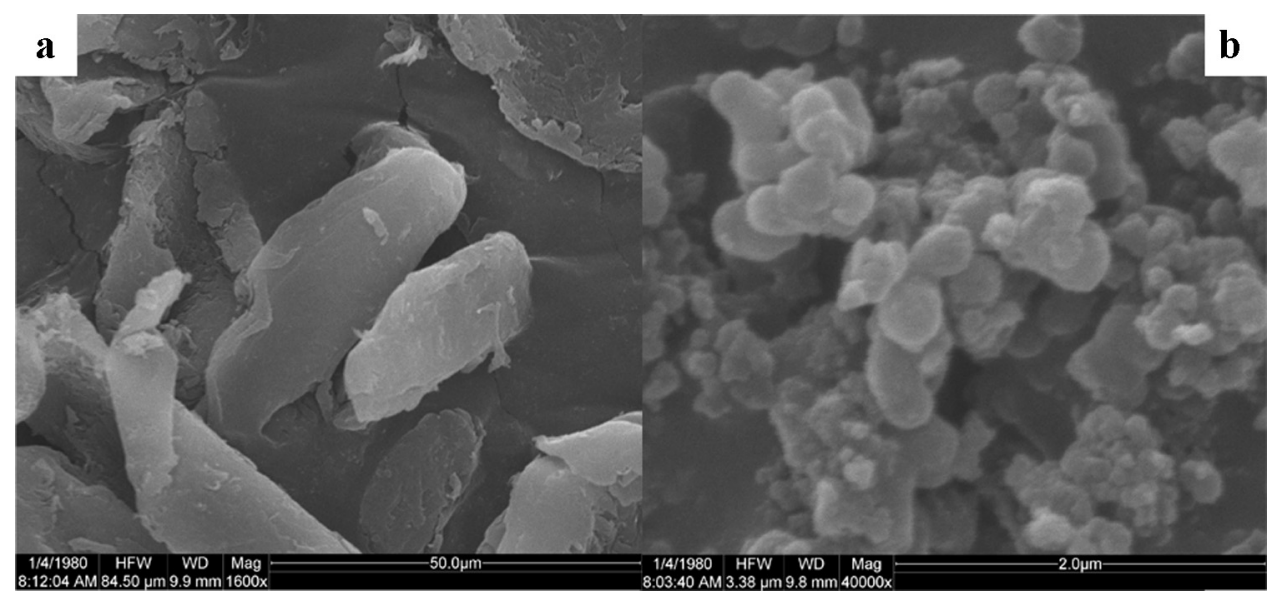

Fig. 1. SEM image of the chitosan (a) and the Ti-CHI (b). 

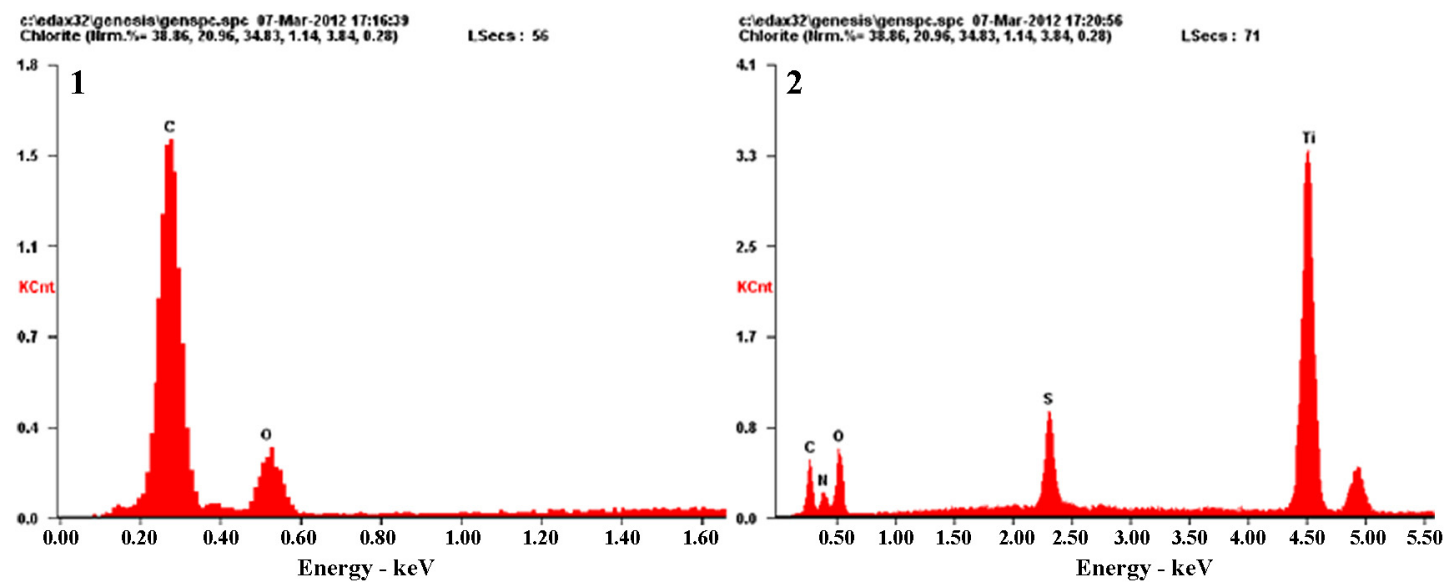

Fig. 2. EDX spectrum of the chitosan and the Ti-CHI.

\subsubsection{FTIR}

FTIR spectroscopy can analyze the organic groups on the surface of these particles. Spectral variations could be observed before and after the fluoride sorption, revealing the adsorption groups on the adsorbents. Fig. 5 shows the FTIR spectra of Ti-CHI before and after fluoride sorption. In the Ti-CHI spectrum, the characteristic bands (3440 and $1635 \mathrm{~cm}^{-1}$ ) represent the stretching vibrations of the $\mathrm{OH}$ group and molecular $\mathrm{H}_{2} \mathrm{O}$, respectively. The band at $2913 \mathrm{~cm}^{-1}$ is assigned to the symmetric stretching of the aliphatic $\mathrm{CH}_{2}$ groups on chitosan [16]. The bands at 1452 and $1328 \mathrm{~cm}^{-1}$ can be assigned to the $\mathrm{C}-\mathrm{N}$ stretching vibration and $\mathrm{C}-\mathrm{H}$ bending modes. The band at $1101 \mathrm{~cm}^{-1}$ is attributed to the $\mathrm{Ti}-\mathrm{OH}$ bond on the $\mathrm{OH}$ groups that coordinate with metal ions [17]. The broad band from 760 to $455 \mathrm{~cm}^{-1}$ is due to the envelope of phonon bands generated by the $\mathrm{Ti}-\mathrm{O}-\mathrm{Ti}$ in the $\mathrm{CHI}$ [16]. The FTIR data for Ti-CHI are similar to

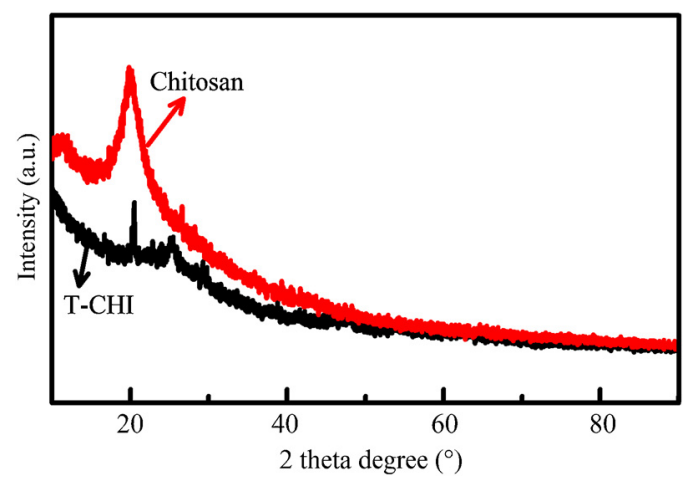

Fig. 3. XRD patterns of the chitosan and the Ti-CHI.

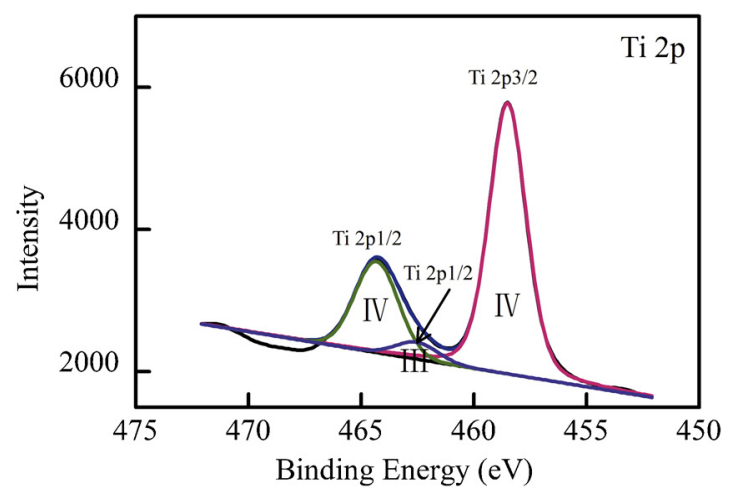

Fig. 4. XPS patterns of the Ti-CHI: curve-fitted as-measured Ti 2p. the data reported for Khan's research. Therefore, the Ti-O-Ti was bonded with $\mathrm{CHI}$ macromolecules through hydrogen and covalent bonding in the Ti-CHI composite. Major variations in the FTIR spectra appear after fluoride sorption at 3376, 1529 and $1411 \mathrm{~cm}^{-1}$. Because the band for the amino $(-\mathrm{NH})$ groups at $3440 \mathrm{~cm}^{-1}$ is masked by the broad adsorption band from the OH group [18], the shift in the band from 3440 to $3376 \mathrm{~cm}^{-1}$ suggests that the $\mathrm{F}^{-}$interacts with the $-\mathrm{NH}$ group. The band at $1529 \mathrm{~cm}^{-1}$ assigned to the $-\mathrm{NH}$ group was revealed after fluoride sorption; the intensity of the band at $1635 \mathrm{~cm}^{-1}$ decreases precipitously, suggesting that the $\mathrm{OH}$ group interacted with $\mathrm{F}^{-}$. The band at $1452 \mathrm{~cm}^{-1}$ (C--N stretch) shifts to $1411 \mathrm{~cm}^{-1}$, indicating that the surface structure of Ti-CHI changes after interacting with $\mathrm{F}^{-}$. Therefore, $\mathrm{F}^{-}$ions adsorb on the $-\mathrm{NH}$ and $-\mathrm{OH}$ groups.

\subsection{Effect of the $F^{-}$initial concentration on sorption}

At the sorbent and sorbate interface, increasing the initial aqueous fluoride concentration could strengthen the ability of the sorbent to capture the sorbate. Therefore, sorption experiments were performed using $\mathrm{Ti}-\mathrm{CHI}$ in aqueous fluoride solutions with different concentrations at constant temperatures (Fig. 6). The initial concentrations were $4.52,9.05,13.57$ and $18.09 \mathrm{mg} / \mathrm{L}$; the sorption primarily occurred within the first $10 \mathrm{~min}$, and the Ti-CHI reached adsorption equilibrium of fluoride in $180 \mathrm{~min}$. Based on these findings, the shaking time in all the further experiments was set as $180 \mathrm{~min}$. The fluoride adsorption capacity of Ti-CHI increased from 4.31 to $11.44 \mathrm{mg} / \mathrm{g}$ as the initial concentration increased. The removal rate was from $63.98 \%$ to $87.50 \%$, showing a high removal efficiency of fluoride on the Ti-CHI. Additionally, at a relatively low

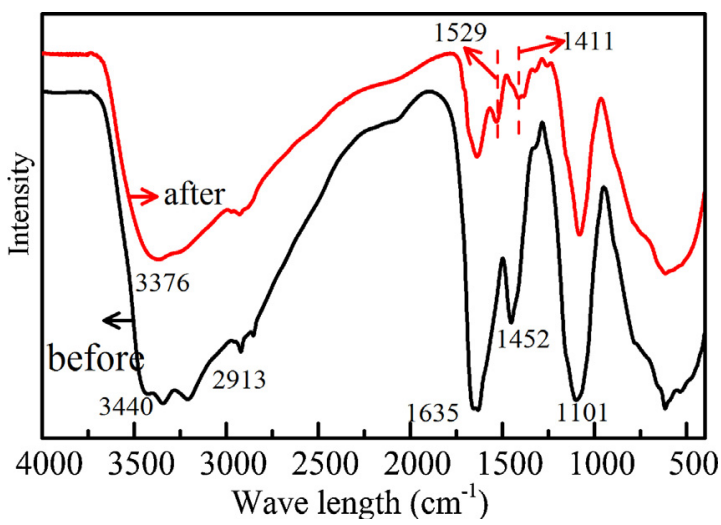

Fig. 5. FTIR spectra of the Ti-CHI before and after the fluoride sorption. 


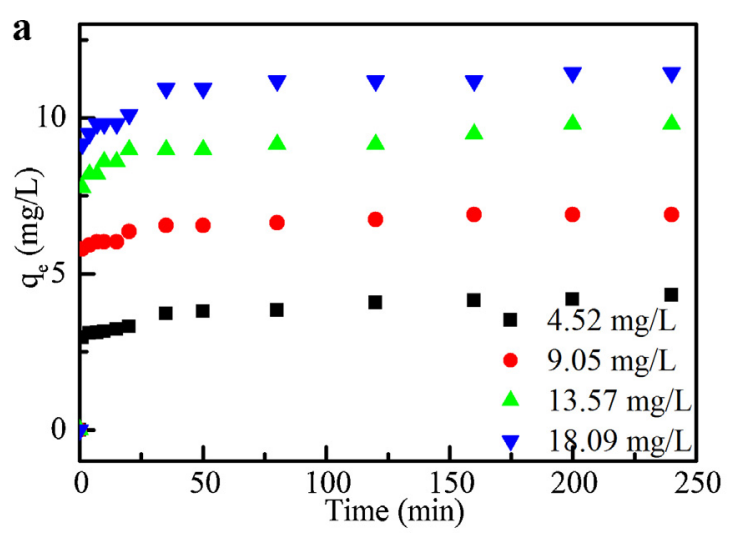

b

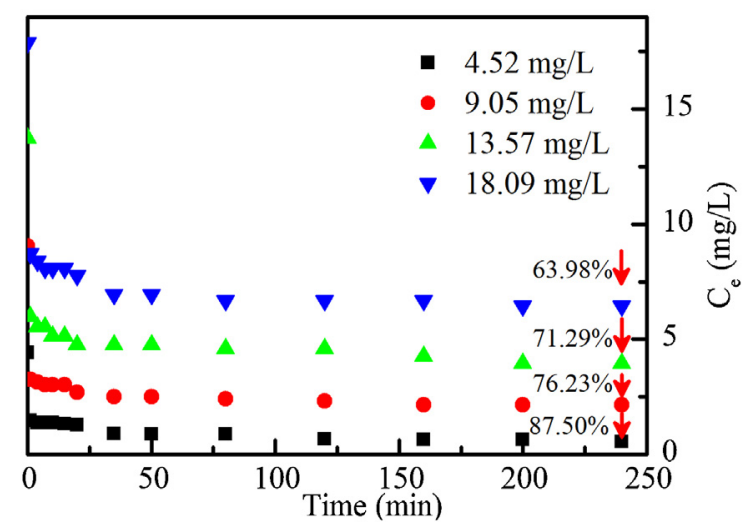

Fig. 6. ( $a$ and b) Effects of the initial fluoride concentration on adsorption.

initial fluoride concentration of $4.52 \mathrm{mg} / \mathrm{L}$, residue fluoride concentration decreased to $0.55 \mathrm{mg} / \mathrm{L}$, which is below the standard of fluoride permitted concentration in drinking water of China $(1.0 \mathrm{mg} / \mathrm{L})$. This suggests that the Ti-CHI may be used for fluoride purification in drinking water.

\subsection{Effect of different coexisting anions on defluoridation}

In natural water, various ions coexist alongside fluoride that may compete for the adsorption sites [16]. To study the effects of different anions on the defluoridation capacity, the $\mathrm{Cl}^{-}, \mathrm{SO}_{4}{ }^{2-}, \mathrm{CO}_{3}{ }^{2-}$, $\mathrm{HCO}_{3}{ }^{-}, \mathrm{NO}_{3}{ }^{-}$and $\mathrm{PO}_{4}{ }^{3-}$ ions that are common in natural water bodies were added to the fluoride aqueous solution as coexisting anions [20,21]. The initial concentrations of the coexisting anions were either $20 \mathrm{mg} / \mathrm{L}, 60 \mathrm{mg} / \mathrm{L}$ and $100 \mathrm{mg} / \mathrm{L}$. The DC of Ti-CHI (Fig. 7) showed that the carbonate, bicarbonate and phosphate reduced

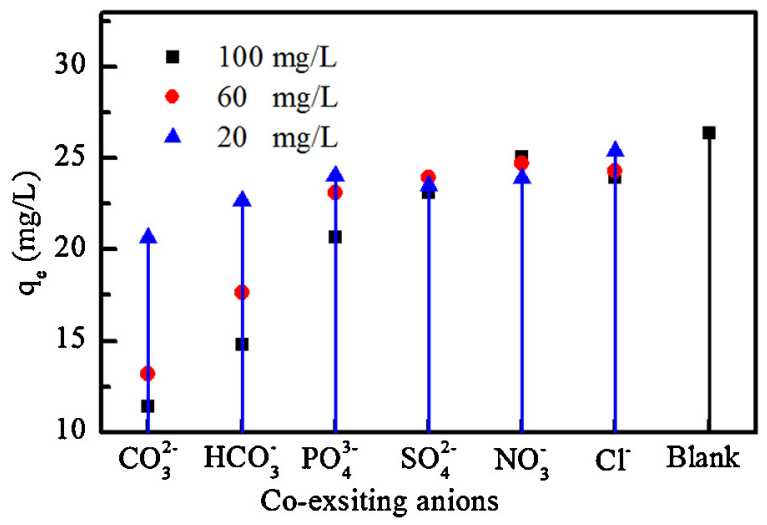

Fig. 7. Defluoridation capacity of Ti-CHI exposed to different anions without adjusting the $\mathrm{pH}$.

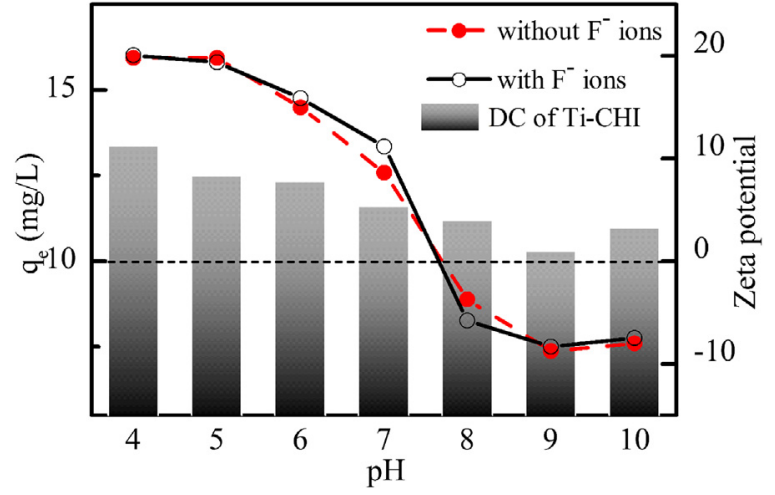

Fig. 8. The effects of fluoride adsorption onto Ti-CHI with different $\mathrm{pH}$ values and the surface charges as determined by the Zeta potential.

the $\mathrm{F}^{-}$sorption capacity, while the other anions had few adverse effects on the fluoride uptake. The adverse effects on the adsorption capacity were as follows: $\mathrm{CO}_{3}{ }^{2-}>\mathrm{HCO}_{3}{ }^{-}>\mathrm{PO}_{4}{ }^{3-}>\mathrm{SO}_{4}{ }^{2-}>\mathrm{Cl}^{-}>\mathrm{NO}_{3}{ }^{-}$. These results were similar to the results reported for a previous study [22]. For $\mathrm{CO}_{3}{ }^{2-}, \mathrm{HCO}^{3-}$ and $\mathrm{PO}_{4}{ }^{3-}$, the fluoride removal efficiency declined as the coexisting ion concentration increased. However, $\mathrm{Cl}^{-}, \mathrm{SO}_{4}{ }^{2-}$ and $\mathrm{NO}_{3}{ }^{-}$did not display the same regularity; the regularity was not applicable for all coexisting ions because the competition capacity of the coexisting anions is usually determined by the changes in the $\mathrm{pH}$, concentration, charge and size of the anions or by a combination of these factors [23].

\subsection{Effect of $\mathrm{pH}$ on defluoridation}

\subsubsection{Evaluation of defluoridation capacity}

The $\mathrm{pH}$ of the solution is critical and controls the adsorption at the water-sorbent interface. Acidic or alkaline solutions can determine the charge of the sorbent directly, affecting the adsorption capacity of the sorbate. Fig. 8 shows the following: (1) the impact of different $\mathrm{pH}$ conditions on the DC and (2) the Zeta potential of the $\mathrm{Ti}-\mathrm{CHI}$ at various pHs before and after fluoride sorption. The DC in $16.69 \mathrm{mg} / \mathrm{L} \mathrm{F} \mathrm{F}^{-}$changed slightly as the initial $\mathrm{pH}$ increased, showing a declining trend overall. The optimal fluoride adsorption occurred at $\mathrm{pH} 4.0$ because at a lower $\mathrm{pH}$, the adsorbent surface was highly protonated, increasing the attractive forces between the positively charged surface and the negatively charged fluoride ions [23]. The DC did not decrease until $\mathrm{pH}=5$, but then declined more slowly when pH larger than 7 . This was because the extra hydroxyl ions will compete with fluoride ions for adsorption sites in the adsorbent surface [24,25]. The highest adsorption capacity occurs at $\mathrm{pH}=4(13.39 \mathrm{mg} / \mathrm{L})$. Because the defluoridation performance of Ti$\mathrm{CHI}$ remains stable from $\mathrm{pH} 4$ to 9 , the Ti-CHI should be an effective defluoridation adsorbent in natural fluoride-contaminated underground water that has a $\mathrm{pH}$ of approximately 8 .

\subsubsection{Surface charge measured using the Zeta potential}

The surface charge of the adsorbents governs the interactions between the adsorbents and the sorbate [26]. The Zeta potential of Ti-CHI with and without $\mathrm{F}^{-}$sorption as the $\mathrm{pH}$ varies from 4 to 10 is shown in Fig. 8. The Zeta potential plots of Ti-CHI before and after fluoride sorption reveal that the $\mathrm{pH}$ value at the zero point of charge $\left(\mathrm{pH}_{\mathrm{ZPC}}\right)$ was approximately 7.8. After exposing the Ti-CHI to $\mathrm{F}^{-}$, the Zeta potential decreases as the $\mathrm{pH}$ values increase and the $\mathrm{DC}$ values decrease. The correlation between the DC and the Zeta potential occurs because the adsorption process is governed by electrostatic adsorption [27]. At $\mathrm{pH}$ values below the $\mathrm{pH}_{\mathrm{ZPC}}$, the adsorbent is positive charged, favoring the adsorption of anionic species $[28,29]$. At the $\mathrm{pH}_{\mathrm{ZPC}}$, the adsorbent is electronically neutral and the 
Table 3

Kinetic parameters for adsorption of fluoride onto Ti-CHI.

\begin{tabular}{|c|c|c|c|c|c|c|}
\hline \multirow[t]{2}{*}{ Initial concentration (mg/g) } & \multicolumn{3}{|c|}{ Pseudo first order model } & \multicolumn{3}{|c|}{ Pseudo second order model } \\
\hline & $k_{1}\left(\mathrm{~h}^{-1}\right)$ & $q_{e 1}(\mathrm{mg} / \mathrm{g})$ & $r^{2}$ & $k_{2}(\mathrm{~g} \mathrm{~h} / \mathrm{mg})$ & $q_{e 2}(\mathrm{mg} / \mathrm{g})$ & $r^{2}$ \\
\hline 4.52 & 97.99 & 3.66 & 0.83 & 32.30 & 3.79 & 0.88 \\
\hline 9.05 & 135.79 & 6.46 & 0.96 & 49.07 & 6.55 & 0.97 \\
\hline 13.57 & 118.88 & 8.98 & 0.96 & 27.78 & 9.13 & 0.97 \\
\hline 18.09 & 119.11 & 10.61 & 0.94 & $-7.70 \mathrm{E}+44$ & 10.50 & 0.92 \\
\hline
\end{tabular}

sorbate with negative charge and is predominantly adsorbed at $\mathrm{pHs}$ below the $\mathrm{pH}_{\mathrm{ZPC}}$. At $\mathrm{pHs}$ above the $\mathrm{pH}_{\mathrm{ZPC}}$, the adsorbent is negative charged and $\mathrm{OH}^{-}$competes for the adsorption sites. Consequently, the adsorption capacity decreases as $\mathrm{pH}$ increases because the electrostatic repulsion is strengthened by the increased negative charge at the surfaces of the adsorbents.

\subsubsection{FTIR of the $\mathrm{pH}$ effect}

Based on the Zeta potential analysis, the Ti-CHI showed different affinity toward $\mathrm{H}^{+}, \mathrm{OH}^{-}$and $\mathrm{F}^{-}$. Therefore, we could identify the adsorption sites on Ti-CHI by comparing the FTIR spectra of Ti-CHI after fluoride sorption at $\mathrm{pH}$ values from 4 to 11. In Fig. 9, variations are observed at $1687,1633,1521,1033 \mathrm{~cm}^{-1}$ that can be assigned to interactions of $\mathrm{Ti}$ ions with the $-\mathrm{NH}$ group, the $\mathrm{OH}$ bond, the $-\mathrm{NH}$ bond and the $\mathrm{Ti}-\mathrm{OH}$ bonds on the three $\mathrm{OH}$ groups, and five $\mathrm{CH}_{2} \mathrm{OH}$ groups on chitosan [16], respectively. As the $\mathrm{pH}$ increases, the band intensities at 1687 and $1521 \mathrm{~cm}^{-1}$ decrease and disappear, respectively; at pHs above 9 and 11 , the band intensity at $1033 \mathrm{~cm}^{-1}$ increases accordingly. These variations imply that the adsorption sites on the surface of the $\mathrm{Ti}-\mathrm{CHI}$ are $-\mathrm{NH}$ and $\mathrm{OH}$ groups. The $-\mathrm{NH}$ groups are protonated under acidic conditions and exhibit a band at $1687 \mathrm{~cm}^{-1}$; therefore, the intensity of this band decreases as the $\mathrm{pH}$ increases. Moreover, the increased $\mathrm{pH}$ generates more $\mathrm{OH}^{-}$ions in the aqueous solution, forming more $\mathrm{Ti}-\mathrm{OH}$ groups and increasing the absorbance intensity of the band at $1033 \mathrm{~cm}^{-1}$. Therefore, the $\mathrm{F}^{-}$adsorption sites on Ti-CHI operate using electrostatic adsorption and are the $-\mathrm{NH}$ and $\mathrm{Ti}-\mathrm{OH}$ groups.

\subsection{Kinetic studies}

To investigate the mechanism of the adsorption process, the Weber and Morris intra-particle diffusion model, the pseudo-firstorder model and the pseudo-second-order model were fitted to the experimental data. The pseudo-first-order model [30] is one of the most popular reaction kinetic models for the liquid-solid adsorption system. It is summarized as follows:

$q=q_{e 1}\left(1-e^{-k_{1} t}\right)$

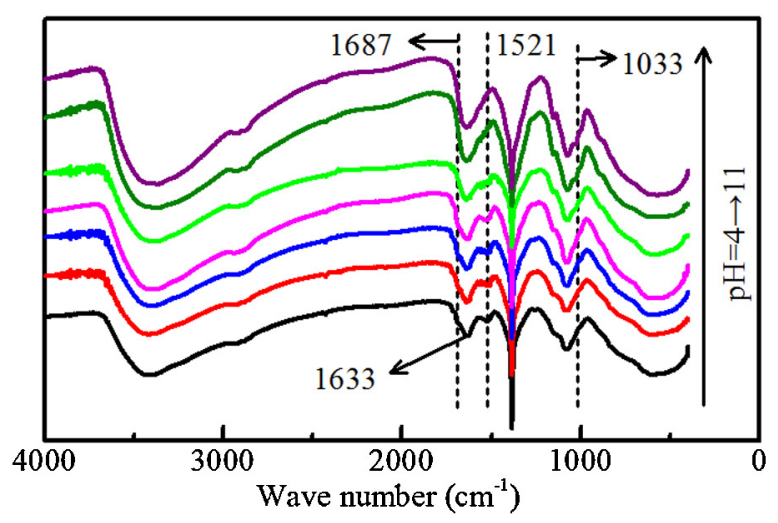

Fig. 9. FTIR spectra of Ti-CHI after fluoride sorption at different $\mathrm{pH}$ values. where $k_{1}$ is the rate constant of the pseudo-first-order model $\left(\mathrm{h}^{-1}\right)$; $q$ is the amount of fluoride ions adsorbed per unit mass of TiCHI $(\mathrm{mg} / \mathrm{g}) ; q_{e 1}$ is the adsorption at equilibrium $(\mathrm{mg} / \mathrm{g})$; and $t$ is the adsorption time $(h)$. The pseudo-second-order model [31,32] is based on the adsorption capacity on the solid phase. The adsorption capacity is proportional to the number of active sites occupied on the adsorbent:

$q=\frac{q_{e 2}^{2} k_{2} t}{1+q_{e 2} k_{2} t}$

where $k_{2}$ is the rate constant of the pseudo-second-order equation ( $\mathrm{gh} / \mathrm{mg}) ; q$ is the amount of fluoride ions adsorbed per unit mass of Ti-CHI $(\mathrm{mg} / \mathrm{g}) ; q_{e 2}$ is the adsorption at equilibrium $(\mathrm{mg} / \mathrm{g})$; and $t$ is the adsorption time $(\mathrm{h})$.

The intra-particle diffusion model proposed by Weber and Morris $[33,34]$ is determined using the linear equation:

$q=k_{I} t^{1 / 2}+C$

where $q$ is the amount of fluoride ions adsorbed per unit mass of $\mathrm{Ti}-\mathrm{CHI}(\mathrm{mg} / \mathrm{g}) ; k_{I}$ is the intra particle diffusion rate constant $\left(\mathrm{h}^{-1 / 2}\right)$; $C$ is the intercept $(\mathrm{mg} / \mathrm{g})$; and $t$ is the adsorption time $(\mathrm{h})$.

The parameters of these models are presented in Tables 3 and 4. The pseudo-second-order model and the Weber and Morris intraparticle diffusion model described the experimental data well. According to the Weber and Morris model, the plot of $q$ versus $t^{1 / 2}$ should be linear if intra-particle diffusion is involved in the adsorption process; if these lines pass through the origin, then the intra particle diffusion is the rate controlling step [35]. Because the $C$ was greater than zero, the plot did not pass through the origin. At this circumstance, adsorption process has two stages which are the initial stage with the higher slope corresponds to the external mass transfer process, and the second stage with the lower slope relates the intra-particle diffusion as a rate limiting step [36]. When the plot does not pass through the origin, there is some extent of boundary layer control, indicating that the intra-particle diffusion process is not the only rate controlling step and that other kinetics models may also control the rate of the adsorption process. Therefore, the mechanism of $\mathrm{F}^{-}$adsorption on Ti-CHI is a combination of chemisorption and electrostatic adsorption.

\subsection{The adsorption equilibrium isotherms}

Studying the adsorption isotherms is very important for understanding the adsorption process. The Langmuir, Freundlich and Langmuir-Freundlich isotherm models are the most commonly employed isotherms used to describe the experimental data

Table 4

Parameters of the intra-particle diffusion model for fluoride adsorption on Ti-CHI.

\begin{tabular}{llll}
\hline Initial concentration $(\mathrm{mg} / \mathrm{g})$ & \multicolumn{3}{l}{ Intra particle diffusion model } \\
\cline { 2 - 4 } & $C(\mathrm{mg} / \mathrm{g})$ & $k_{I}\left(\mathrm{~h}^{-0.5}\right)$ & $r^{2}$ \\
\hline 4.52 & 2.93 & 0.74 & 0.94 \\
9.05 & 5.85 & 0.61 & 0.90 \\
13.57 & 8.04 & 0.92 & 0.88 \\
18.09 & 9.40 & 1.20 & 0.84 \\
\hline
\end{tabular}


Table 5

Parameters for the Langmuir, Freundlich and Langmuir-Freundlich isotherms for fluoride adsorption on Ti-CHI.

\begin{tabular}{|c|c|c|c|c|c|c|c|c|c|c|}
\hline \multirow[t]{2}{*}{ Temperature (K) } & \multicolumn{3}{|c|}{ Langmuir } & \multicolumn{3}{|c|}{ Freundlich } & \multicolumn{4}{|c|}{ Langmuir-Freundlich } \\
\hline & $q_{\max }$ & $k_{L}$ & $r^{2}$ & $k_{F}$ & $n$ & $r^{2}$ & $q_{L F-\max }$ & $k_{L F}$ & $b_{L F}$ & $r^{2}$ \\
\hline 283 & 14.32 & 0.36 & 0.997 & 4.22 & 2.44 & 0.936 & 14.12 & -0.60 & -0.60 & 0.996 \\
\hline 293 & 14.16 & 0.36 & 0.993 & 4.20 & 2.42 & 0.940 & 14.16 & -0.60 & -0.60 & 0.991 \\
\hline 303 & 15.10 & 0.60 & 0.974 & 5.64 & 2.74 & 0.880 & 15.10 & 0.78 & 0.78 & 0.965 \\
\hline 313 & 15.31 & 0.62 & 0.969 & 5.80 & 2.79 & 0.854 & 15.31 & 0.80 & 0.79 & 0.959 \\
\hline 323 & 16.12 & 0.77 & 0.999 & 5.86 & 2.58 & 0.932 & 16.12 & 1.03 & 0.75 & 0.999 \\
\hline
\end{tabular}

collected during the adsorption process. The Langmuir isotherm model assumes that there is monolayer adsorption onto a surface with a finite number of uniform adsorption sites [37].

$q_{e}=\frac{q_{\max } c_{e}}{1+k_{L} c_{e}}$

The Freundlich isotherm model is an empirical equation based on adsorption on a heterogeneous surface [38].

$q_{e}=k_{F} c_{e}^{1 / n}$

where $c_{e}$ is the equilibrium concentration of $\mathrm{F}^{-}$in the solutions $(\mathrm{mg} / \mathrm{L}) ; q_{\max }$ is the maximum adsorption capacity of fluoride ions $(\mathrm{mg} / \mathrm{g})$; and $k_{L}$ is the Langmuir constant $(\mathrm{L} / \mathrm{mg})$. The terms $k_{F}$ and $1 / n$ are Freundlich constants that indicate the extent of adsorption and the adsorption intensity.

The Langmuir-Freundlich model is a combination of the above models [39-41]. This model could be expressed as follows:

$q_{e}=\frac{q_{L F-\max }\left(k_{L F} c_{e}\right) b_{L F}}{1+\left(k_{L F} c_{e}\right) b_{L F}}$

where $q_{L F-\max }(\mathrm{mg} / \mathrm{g}), k_{L F}(\mathrm{~L} / \mathrm{mg})$ and $b_{L F}$ are the maximum adsorption capacity and Langmuir-Freundlich isotherm constants.

Transforming nonlinear isotherms to their linear forms implicitly may alter their error structure and violate the error variance, as
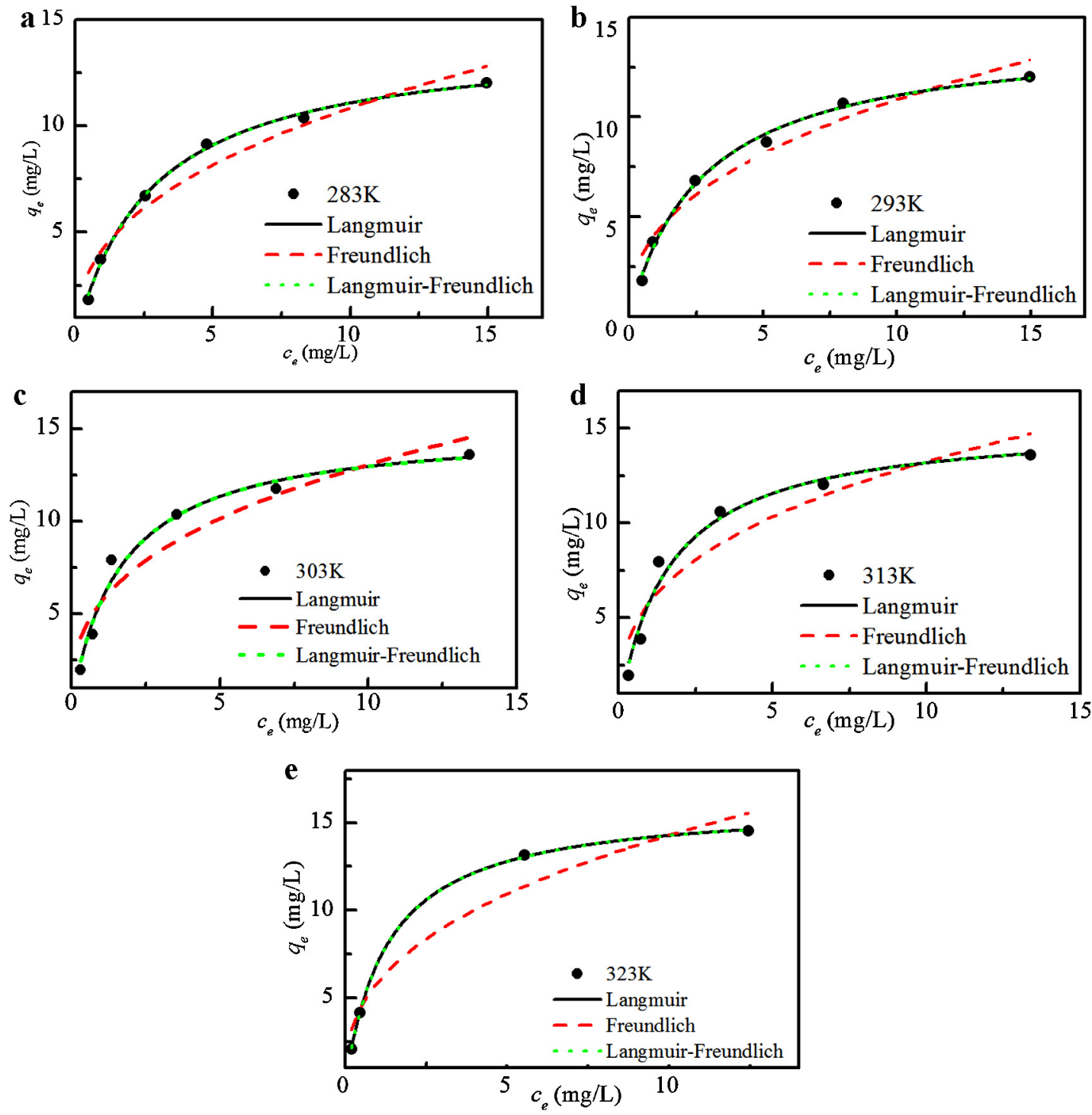

Fig. 10. (a-e) Non linear fits of the experimental data to the adsorption isotherms at 283, 293, 303, $313,323 \mathrm{~K}$, respectively. 
Table 6

Thermodynamic parameters of fluoride adsorption on Ti-CHI.

\begin{tabular}{lcccc}
\hline$T$ & $K_{\mathrm{L}}$ & $\Delta G^{\circ}$ & $\Delta H^{\circ}$ & $\Delta S^{\circ}$ \\
\hline 283 & 6.84 & -4.5 & 15.7 & 71 \\
293 & 6.84 & -4.7 & & \\
303 & 11.4 & -6.1 & & \\
313 & 11.78 & -6.4 & & \\
323 & 14.63 & -7.2 & & \\
\hline
\end{tabular}

well the normality assumptions of standard least squares [24]. Nonlinear optimization is a more complex mathematical method but is more accurate for determining the isotherm parameter values [42]. There is no problem with transforming nonlinear isotherms to linear forms, and they had the same error structures when the bestfitting isotherms are compared [43]. The nonlinear results were presented in Table 5.

According to the $r^{2}$ value of the nonlinear regression methods, the Langmuir and the Langmuir-Freundlich isotherms had identical coefficients of determination that exceeded those of the Freundlich isotherm. Fig. 10(a-e) presents the isotherm models of the adsorption process. The data given in Table 4 shows that when the temperature increases from $283 \mathrm{~K}$ to $323 \mathrm{~K}$, the $\mathrm{F}^{-}$adsorption increased from 14.32 to $16.12 \mathrm{mg} / \mathrm{g}$. The high DC of Ti-CHI shows that it could be an effective adsorbent to remove fluoride from drinking water.

\subsection{Thermodynamic studies}

The increase in DC as the temperature increases may occur because the higher temperature enhances the binding tendency of the $\mathrm{F}^{-}$ions onto the interface, thus increasing the extent of adsorption [44]. Thermodynamic studies show whether the adsorption process is spontaneous [45]. The thermodynamic spontaneity and feasibility was assessed by calculating the three basic thermodynamic parameters, i.e., standard free energy change $\left(\Delta G^{\circ}\right)$, enthalpy change $\left(\Delta H^{\circ}\right)$ and entropy change $\left(\Delta S^{\circ}\right)$, using the following equations [46] [47]:

$\Delta G^{\mathrm{o}}=-R T \ln K_{L}$

$\ln K_{L}=\frac{\Delta S^{\mathrm{o}}}{R}-\frac{\Delta H^{\mathrm{o}}}{R T}$

$\Delta G^{\mathrm{o}}=\Delta H^{\mathrm{o}}-T \Delta S^{\mathrm{o}}$

where $R$ is the universal gas constant $(8.314 \mathrm{~J} / \mathrm{mol} \mathrm{K}), T$ is the absolute temperature $(\mathrm{K})$, and $K_{L}$ is the adsorption equilibrium constant of the Langmuir isotherm obtained from the nonlinear method. A plot of $\Delta G^{\circ}$ versus $T$ will be linear, and the values of $\Delta H^{\circ}$ and $\Delta S^{\circ}$ are determined using the slope and intercept of that plot; the linear correlation coefficient of the plot is 0.95 and the data are summarized in Table 6 . The $\Delta G^{\circ}$ values are negative from 283 to $323 \mathrm{~K}$. The negative values confirm the feasibility of the process and the spontaneous nature of the adsorption. Moreover, the absolute values of $\Delta G^{\circ}$ increase from 4.5 to $7.2 \mathrm{~kJ} / \mathrm{mol}$ as the temperature rises, indicating that the fluoride adsorption process on Ti-CHI becomes more favorable at higher temperatures [48]. The $\Delta H^{\circ}$ value given in Table 6 is positive, indicating that the adsorption reaction is endothermic. The positive $\Delta S^{\circ}$ value reflects the affinity of the Ti$\mathrm{CHI}$ for the fluoride and suggests that some structural changes occur in Ti-CHI [49].

\section{Conclusions}

The titanium(IV) hydrate material based on a chitosan template is a cost effective bio-adsorbent for defluoridating aqueous solutions. Sorption experiments showed the following results: $\mathrm{Ti}-\mathrm{CHI}$ could remove fluoride from aqueous solutions with low fluoride concentrations $(4.52 \mathrm{mg} / \mathrm{L})$, making water meeting the permitted drinking water standard $(0.55 \mathrm{mg} / \mathrm{L}$, below $1 \mathrm{mg} / \mathrm{L})$; the Ti-CHI had an effective defluoridation capacity in a wide $\mathrm{pH}$ range (4-9) and is a potential adsorbent for natural fluoride-contaminated water with a basic $\mathrm{pH}$; and finally, the presence of anions had a deleterious effect on the adsorption of fluoride, particularly for $\mathrm{CO}_{3}{ }^{2-}, \mathrm{HCO}_{3}{ }^{-}$and $\mathrm{PO}_{4}{ }^{3-}$. After combining the defluoridation effect, the $\mathrm{pH}$ effect and the analysis of the FTIR and Zeta potential data, we found that the adsorption process was governed by both electrostatic adsorption and chemical bonding: the $-\mathrm{NH}$ groups and $\mathrm{Ti}-\mathrm{OH}$ groups were the adsorption sites for $\mathrm{F}^{-}$on Ti-CHI. The kinetic studies showed that the experimental data fit both the pseudo-second-order and Weber and Morris intra-particle diffusion models. The Langmuir and Langmuir-Freundlich isotherms described the experimental data well, indicating that the maximum adsorption capacity for fluoride on Ti-CHI was $16.12 \mathrm{mg} / \mathrm{g}$. The thermodynamic studies revealed that the fluoride adsorption process on Ti-CHI was spontaneous. Therefore, $\mathrm{Ti}-\mathrm{CHI}$ is an economical adsorbent free of energy driving.

\section{Acknowledgements}

This work is supported by Program for New Century Excellent Talents in University, Ministry of Education, China (NCET-12-0429) and the Fundamental Research Fund for the Central Universities (2012205020209).

\section{References}

[1] J. Hoinkis, S. Valero-Freitag, M.P. Caporgno, C. Patzold, Removal of nitrate and fluoride by nanofiltration - a comparative study, Desalin. Water Treat. 30 (2011) 278-288.

[2] Z. Mandinic, M. Curcic, B. Antonijevic, M. Carevic, J. Mandic, D. Djukic-Cosic, C.P. Lekic, Fluoride in drinking water and dental fluorosis, Sci. Total Environ. 408 (2010) 3507-3512.

[3] I. Bejaoui, A. Mnif, B. Hamrouni, Influence of operating conditions on the retention of fluoride from water by nanofiltration, Desalin. Water Treat. 29 (2011) $39-46$.

[4] S. Jagtap, M.K. Yenkie, N. Labhsetwar, S. Rayalus, Fluoride in drinking water and defluoridation of water, Chem. Rev. 112 (2012) 2454-2466.

[5] A. Yuchi, K. Matsuo, Adsorption of anions to zirconium(IV) and titanium(IV) chemically immobilized on gel-phase, J. Chromatogr. A 1082 (2005) 208-213.

[6] T. Wajima, Y. Umeta, S. Narita, K. Sugawara, Adsorption behavior of fluoride ions using a titanium hydroxide-derived adsorbent, Desalination 249 (2009) 323-330.

[7] L. Chen, B.Y. He, S. He, T.J. Wang, C.L. Su, Y. Jin, Fe-Ti oxide nano-adsorbent synthesized by co-precipitation for fluoride removal from drinking water and its adsorption mechanism, Powder Technol. 227 (2012) 3-8.

[8] B. Lindholm-Sethson, B.I. Ardlin, Effects of $\mathrm{pH}$ and fluoride concentration on the corrosion of titanium, J. Biomed. Mater. Res. A 86A (2008) 149-159.

[9] D. Thakre, S. Jagtap, N. Sakhare, N. Labhsetwar, S. Meshram, S. Rayalu, Chitosan based mesoporous Ti-Al binary metal oxide supported beads for defluoridation of water, Chem. Eng. J. 158 (2010) 315-324.

[10] S. Jagtap, D. Thakre, S. Wanjari, S. Kamble, N. Labhsetwar, S. Rayalu, New modified chitosan-based adsorbent for defluoridation of water, J. Colloid Interface Sci. 332 (2009) 280-290

[11] L. Chen, S. He, B.-Y. He, T.-J. Wang, C.-L. Su, C. Zhang, Y. Jin, Synthesis of irondoped titanium oxide nanoadsorbent and its adsorption characteristics for fluoride in drinking water, Ind. Eng. Chem. Res. 51 (2012) 13150-13156.

[12] R. Khan, M. Dhayal, Electrochemical studies of novel chitosan/TiO 2 bioactive electrode for biosensing application, Electrochem. Commun. 10 (2008) 263-267.

[13] C. Malitesta, G. Razzini, L. Peraldo Bicelli, L. Sabbatini, Photoelectrochemical behaviour and XPS characterization of $(\mathrm{Ti}, \mathrm{Al}, \mathrm{V}) \mathrm{O}_{2}$ film obtained by nonconventional anodic oxidation of a commercial Ti-Al-V alloy, Int. J. Hydrogen Energy 12 (1987) 219-225.

[14] D. Borgmann, E. Hums, G. Hopfengartner, G. Wedler, G.W. Spitznagel, I. Rademacher, XPS studies of oxidic model catalysts: internal standards and oxidation numbers, J. Electron Spectrosc. 63 (1993) 91-116.

[15] I. Le, R. Strydom, S. Hofmann, The contribution of characteristic energy losses in the core-level X-ray photoelectron spectroscopy peaks of TiN and (Ti,Al)N studied by electron energy loss spectroscopy and X-ray photoelectron spectroscopy, J. Electron Spectrosc. 56 (1991) 85-103.

[16] R. Khan, M. Dhayal, Nanocrystalline bioactive $\mathrm{TiO}_{2}$-chitosan impedimetric immunosensor for ochratoxin-A, Electrochem. Commun. 10 (2008) 492-495. 
[17] A.J. Varma, S.V. Deshpande, J.F. Kennedy, Metal complexation by chitosan and its derivative: a review, Carbohydr. Polym. 55 (2004) 77-93.

[18] A.T. Pauline, J.I. Simionato, J.C. Garcia, J. Nozaki, Characterization of chitosan and chitin produced from silkworm chrysalides, Carbohydr. Polym. 64 (2006) 98-103.

[19] P. Garg, S. Chaudhari, Adsorption of fluoride from drinking water on magnesium substituted hydroxyapatite, in: 2012 International Conference on Future Environment and Energy, 2012, pp. 180-185.

[20] S.P. Kamble, G. Deshpande, P.P. Barve, S. Rayalu, N.K. Labhsetwar, A. Malyshew, B.D. Kulkarni, Adsorption of fluoride from aqueous solution by alumina of alkoxide nature: batch and continuous operation, Desalination 264 (2010) $15-23$.

[21] N. Viswanathan, S. Meenakshi, Selective fluoride adsorption by a hydrotalcite/chitosan composite, Appl. Clay Sci. 48 (2010) 607-611.

[22] G. Alagumuthu, M. Rajan, Kinetic and equilibrium studies on fluoride removal by zirconium (iv)-impregnated groundnut shell carbon, Hem. Ind. 64 (2010) 295-304.

[23] X.T. Xu, Q. Li, H. Cui, J.F. Pang, L. Sun, H. An, J.P. Zhai, Adsorption of fluoride from aqueous solution on magnesia-loaded fly ash cenospheres, Desalination 272 (2011) 233-239.

[24] Y.S. Ho, Second-order kinetic model for the sorption of cadmium onto tree fern: a comparison of linear and non-linear methods, Water Res. 40 (2006) 119-125.

[25] C.S. Sundaram, N. Viswanathan, S. Meenakshi, Defluoridation chemistry of synthetic hydroxyapatite at nano scale: equilibrium and kinetic studies, J. Hazard. Mater. 155 (2008) 206-215.

[26] H.H. Salih, C.L. Patterson, G.A. Sorial, R. Sinha, R. Krishnan, The implication of iron oxide nanoparticles on the removal of trichloroethylene by adsorption, Chem. Eng. J. 193 (2012) 422-428.

[27] X.M. Dou, D. Mohan, C.U. Pittman, S. Yang, Remediating fluoride from water using hydrous zirconium oxide, Chem. Eng. J. 198 (2012) 236-245.

[28] N.I. Chubar, V.A. Kanibolotskyy, V.V. Strelko, G.G. Gallios, V.F. Samanidou, T.O. Shaposhnikova, V.G. Milgrandt, I.Z. Zhuravlev, Adsorption of phosphate ions on novel inorganic ion exchangers, Colloids Surf. A 255 (2005) 55-63.

[29] A.F.d. Sousa, T.P. Braga, E.C.C. Gomes, A. Valentini, E. Longhinotti, Adsorption of phosphate using mesoporous spheres containing iron and aluminum oxide, Chem. Eng. J. 210 (2012) 143-149.

[30] S. Lagergren, About the theory of so called adsorption of soluble substances, Kungliga Svenska Vetenskapsakademiens, Band 24, 24 ed., Handlingar, 1898.

[31] Y.S. Ho, J.C.Y. Ng, G. McKay, Kinetics of pollutants sorption by biosorbents: review, Sep. Purif. Methods 29 (2000) 189-232.

[32] S.S. Gupta, K.G. Bhattacharyya, Kinetics of adsorption of metal ions on inorganic materials: a review, Adv. Colloid Interface Sci. 162 (2011) 39-58.
[33] W.J. Weber, J.C. Morris, Kinetics of adsorption on carbon from solution, J. San. Eng. Div. 89 (1962) 31-39.

[34] P.S. Kumar, S. Ramalingam, S.D. Kirupha, A. Murugesan, T. Vidhyadevi, S. Sivanesan, Adsorption behavior of nickel(II) onto cashew nut shell: equilibrium, thermodynamics, kinetics, mechanism and process design, Chem. Eng. J. 167 (2011) 122-131.

[35] J.P. Chen, S. Wu, K.H. Chong, Surface modification of a granular activated carbon by nitric acid for enhancement of copper adsorption, Carbon 41 (2003) 1979-1986.

[36] M.V. Subbaiah, Y. Vijaya, N.S. Kumar, A.S. Reddy, A. Krishnaiah, Biosorption of nickel from aqueous solutions by Acacia leucocephala bark: kinetics and equilibrium studies, Colloids Surf. B 74 (2009) 260-265.

[37] I. Langmuir, The adsorption of gases on plane surfaces of glass, mica and platinum, J. Am. Chem. Soc. 40 (1918) 1361-1403.

[38] H.M.F. Freundlich, Über die adsorption in lösungen, Z. Phys. Chem. 57A (1906) $385-470$.

[39] D.D. Do, Adsorption Analysis: Equilibria and Kinetics, Imperial College Press, London, 1998.

[40] A. Shafaei, F.Z. Ashtiani, T. Kaghazchi, Equilibrium studies of the sorption $\mathrm{Hg}$ (II) ions onto chitosan, Chem. Eng. J. 133 (2007) 311-316.

[41] E. Guibal, Interactions of metal ions with chitosan-based sorbents: a review, Sep. Purif. Technol. 38 (2004) 43-74.

[42] Y.S. Ho, A.E. Ofomaja, Kinetics and thermodynamics of lead ion sorption on palm kernel fibre from aqueous solution, Process Biochem. 40 (2005) 3455-3461.

[43] Y.S. Ho, Isotherms for the sorption of lead onto peat: comparison of linear and non-linear methods, Pol. J. Environ. Stud. 15 (2006) 81-86.

[44] M. Mohapatra, D. Hariprasad, L. Mohapatra, S. Anand, B.K. Mishra, Mg-doped nano ferrihydrite-a new adsorbent for fluoride removal from aqueous solutions, Appl. Surf. Sci. 258 (2012) 4228-4236.

[45] S. Hong, C. Wen, J. He, F. Gan, Y.-S. Ho, Adsorption thermodynamics of methylene blue onto bentonite, J. Hazard. Mater. 167 (2009) 630-633.

[46] Y.S. Ho, T.H. Chiang, Y.M. Hsueh, Removal of basic dye from aqueous solution using tree fern as a biosorbent, Process Biochem. 40 (2005) 119-124.

[47] Y.S. Ho, Removal of copper ions from aqueous solution by tree fern, Water Res. 37 (2003) 2323-2330.

[48] A.B. Zaki, M.Y. El-Sheikh, J. Evans, S.A. El-Safty, Kinetics and mechanism of the sorption of some aromatic amines onto amberlite IRA-904 anion-exchange resin, J. Colloid Interface Sci. 221 (2000) 58-63.

[49] V.K. Gupta, Equilibrium uptake, sorption dynamics, process development, and column operations for the removal of copper and nickel from aqueous solution and wastewater using activated slag, a low-cost adsorbent, Ind. Eng. Chem. Res. 37 (1998) 192-202. 